\title{
Editorial
}

\section{Actuarial and Financial Risks: Models, Statistical Inference, and Case Studies}

\author{
Ričardas Zitikis, ${ }^{1}$ Edward Furman, ${ }^{2}$ Abdelhakim Necir, ${ }^{3}$ \\ Johanna Nešlehová, ${ }^{4}$ and Madan L. Purii, 6 \\ ${ }^{1}$ Department of Statistical and Actuarial Sciences, University of Western Ontario, London, \\ ON, Canada N6A $3 K 7$ \\ ${ }^{2}$ Department of Mathematics and Statistics, York University, Toronto, ON, Canada M3J 1P3 \\ ${ }^{3}$ Laboratory of Applied Mathematics, Mohamed Khider University, Biskra 07000, Algeria \\ ${ }^{4}$ Department of Mathematics and Statistics, McGill University, Motreal, QC, Canada H3A 2K6 \\ ${ }^{5}$ Department of Mathematics and Statistics, King Fahd University of Petroleum and Minerals, \\ Dhahran 31261, Saudi Arabia \\ ${ }^{6}$ Department of Mathematics, Indiana University, Bloomington, Indiana 47405, USA
}

Correspondence should be addressed to Ričardas Zitikis, zitikis@stats.uwo.ca

Received 10 June 2010; Accepted 10 June 2010

Copyright (C) 2010 Ričardas Zitikis et al. This is an open access article distributed under the Creative Commons Attribution License, which permits unrestricted use, distribution, and reproduction in any medium, provided the original work is properly cited.

Understanding actuarial and financial risks poses major challenges. The need for reliable approaches to risk assessment is particularly acute in the present context of highly uncertain financial markets. New regulatory guidelines such as the Basel II Accord for banking and Solvency II for insurance are being implemented in many parts of the world. Regulators in various countries are adopting risk-based approaches to the supervision of financial institutions.

Many researchers in a variety of areas have been dealing with nontrivial and highly multifaceted problems in an attempt to answer seemingly plain questions such as how to assess and quantify risks (Crouhy, Galai, and Mark [1]). The present issue of the Journal of Probability and Statistics provides a glimpse of how challenging such problems are, both philosophically and mathematically, through a collection of papers that cover a large spectrum of applied and theoretical problems.

A number of ideas concerning measuring risks stem from the economic theory and in particular from the classical utility theory (Neumann and Morgenstern [2]) as well as from the prospect theory (Kahneman and Tversky [3]), which were subsequently developed into the anticipated, also known as rank-dependent or generalized expected, utility theory (Quiggin [4]), and most recently into a ground-breaking theory of choice under uncertainty that allows for the presence of catastrophic risks (Chichilnisky [5]). 
This special Journal of Probability and Statistics issue offers many articles based on such economic theories and their extensions. G. Chichilnisky develops foundations for dealing with catastrophic risks, called "black swans", which require tools beyond the classical $\sigma$-additive probability theory. M. Finke, E. Belasco, and S. Huston review household property risk management theory in order to compare optimal risk retention to conventional practice. Aided with ideas of behavioral economics and finance, H. Takahashi investigates the forecast accuracy of fundamental values in financial markets and clarifies issues such as price fluctuations. F. Greselin, L. Pasquazzi, and R. Zitikis develop statistical inference for Zenga's index of economic inequality, whose construction brings to mind the relative nature of notions such as small and large, poor and rich.

To make us aware of the scope and complexity of the problem, several authors have contributed papers tackling risks within and beyond the financial sector. G. Chichilnisky and P. Eisenberger have written a far-reaching article on asteroid risks. They convince us about the critical importance of these risks, for which very little research has been carried out, and they provide an interesting methodology for comparing asteroid risks with the risks of climate change to make better decisions about research and development. For further information on this and other related topics, we refer to the web site http://www.chichilnisky.com/.

W. J. Braun, B. L. Jones, J. S. W. Lee, D. G. Woolford, and M. Wotton examine the risk assessment of forest fires in order to generate burn probability risk maps, concentrating on the district municipality of Muskoka in Ontario, Canada, as an illustrative example. D. L. K. Hoag and J. Parsons discuss their new program, Risk Navigator SRM, which greatly expands the number of managers that can address risks in agriculture. The program lays down solid foundations and provides state-of-the-art practical support tools, including a web site (http://www.risknavigatorsrm.com/), a risk management simulator (http:/ /www.agsurvivor.com/), and a book that puts it all together (Hoag [6]).

Specific insurance risk-related problems are tackled by a number of authors. P. Gaillardetz develops an elaborate evaluation approach to equity-linked insurance products under stochastic interest rates. O. Furman and E. Furman propose layer-based counterparts of a number of risk measures and investigate their properties and analytic tractability, especially within the framework of exponential dispersion models.

One of the basic measures of risk is the so-called value-at-risk, which amounts to a high quantile from the statistical point of view. It is arguably one of the most challenging measures to estimate and to work with in practice. This risk measure was advocated by the Basel Committee on Banking Supervision (http://www.bis.org/bcbs/) and implemented worldwide. C. Gouriéroux and J. Jasiak suggest and develop a novel nonparametric method for estimating the conditional value-at-risk and illustrate its performance on real-life portfolio returns. G. Dmitrasinovic-Vidovic, A. Lari-Lavassani, X. Li, and A. Ware explore the conditional capital-at-risk measure in the context of portfolio optimization and offer optimal strategies.

This special Journal of Probability and Statistics issue also includes papers that develop statistical inference for distortion risk measures and related quantities in the case of heavy-tailed distributions. A. Necir and D. Meraghni deal with the estimation of $L$ functionals, which are generalizations of the distortion risk measure, and which naturally arise in the aforementioned anticipated utility theory. A. Necir, A. Rassoul, and D. Meraghni develop a theory for estimating the renewal function of interoccurrence times of heavy-tailed risks. A. Necir, A. Rassoul, and R. Zitikis introduce a new estimator of the conditional tail expectation, which is one of the most important examples of the distortion risk measure and 
demonstrate the performance of the new estimator within the framework of heavy-tailed risks.

We, the editors of this special issue, most sincerely thank three groups of people, without whom this special issue would not have reached its fruition: first and foremost, the authors who have shared with us their research achievements; second, the helpful and efficient Hindawi Publishing Corporation staff; third, the professional and diligent referees whose efforts resulted in useful feedback incorporated into often several rounds of revisions of the herein published papers. We are also grateful to various granting agencies (the Actuarial Foundation, the Actuarial Education and Research Fund, the Society of Actuaries Committee on Knowledge Extension Research, and the Natural Sciences and Engineering Research Council of Canada) for their support of our research.

Ričardas Zitikis

Edward Furman

Abdelhakim Necir

Johanna Nešlehová

Madan L. Puri

\section{References}

[1] M. Crouhy, D. Galai, and R. Mark, The Essentials of Risk Management, McGraw-Hill, NY, USA, 2006.

[2] J. von Neumann and O. Morgenstern, Theory of Games and Economic Behavior, Princeton University Press, Princeton, NJ, USA, 1944.

[3] D. Kahneman and A. Tversky, "Prospect theory: an analysis of decision under risk," Econometrica, vol. 47, pp. 263-291, 1979.

[4] J. Quiggin, Generalized Expected Utility Theory, Kluwer Academic, Dodrecht, The Netherlands, 1993.

[5] G. Chichilnisky, "An axiomatic approach to choice under uncertainty with catastrophic risks," Resource and Energy Economics, vol. 22, no. 3, pp. 221-231, 2000.

[6] D. L. Hoag, Applied Risk Management in Agriculture, CRC Press, Boca Raton, Fla, USA, 2009. 


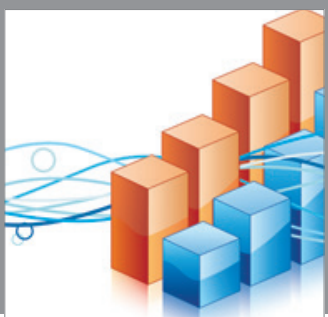

Advances in

Operations Research

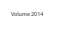

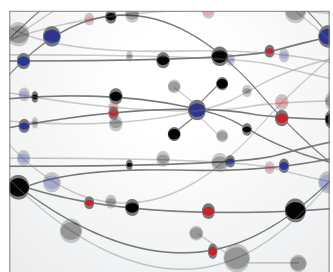

\section{The Scientific} World Journal
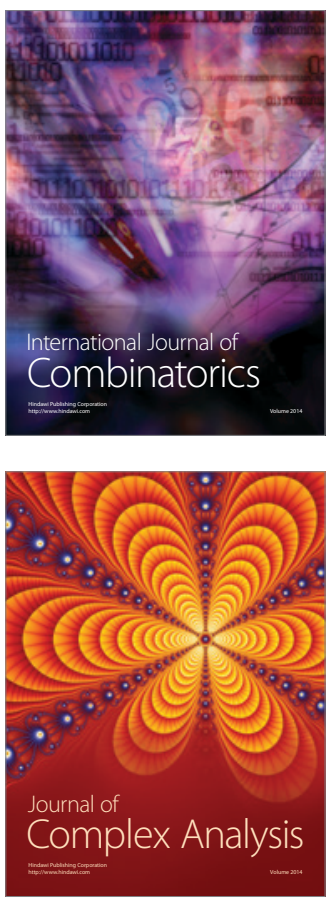

International Journal of

Mathematics and

Mathematical

Sciences
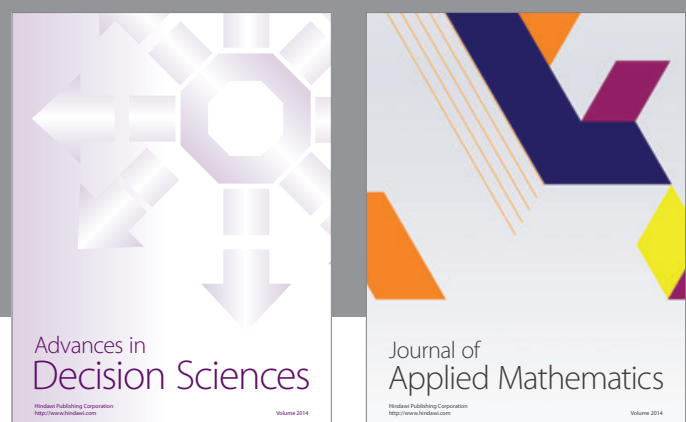

Journal of

Applied Mathematics
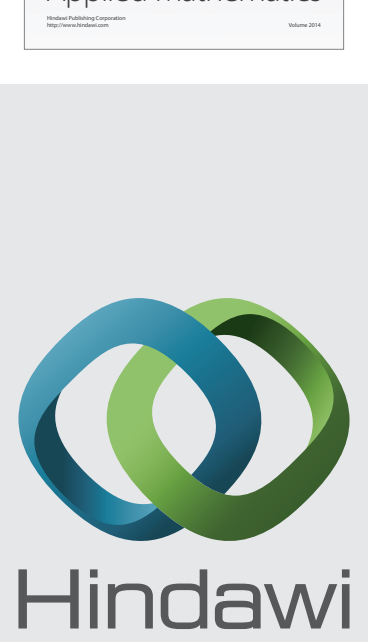

Submit your manuscripts at http://www.hindawi.com
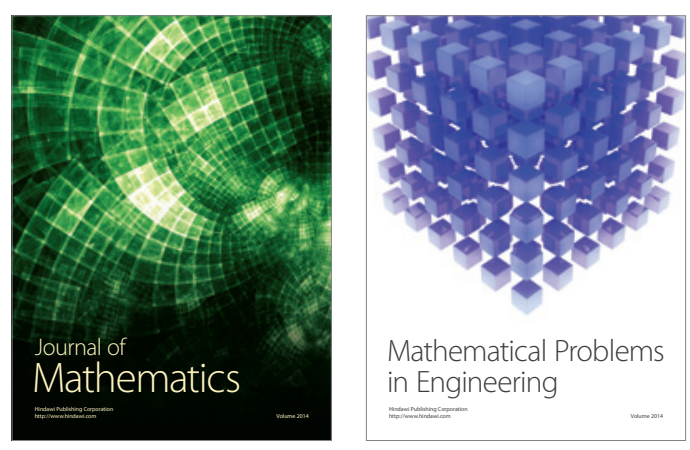

Mathematical Problems in Engineering
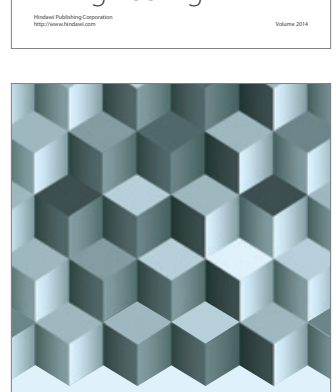

Journal of

Function Spaces
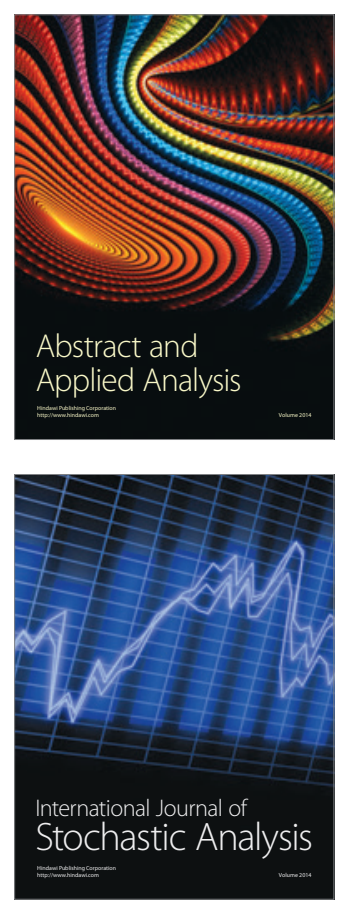

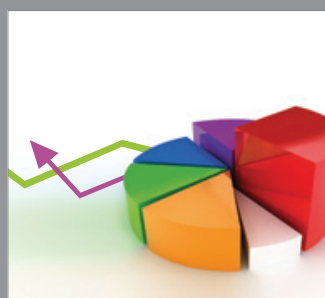

ournal of

Probability and Statistics

Promensencen
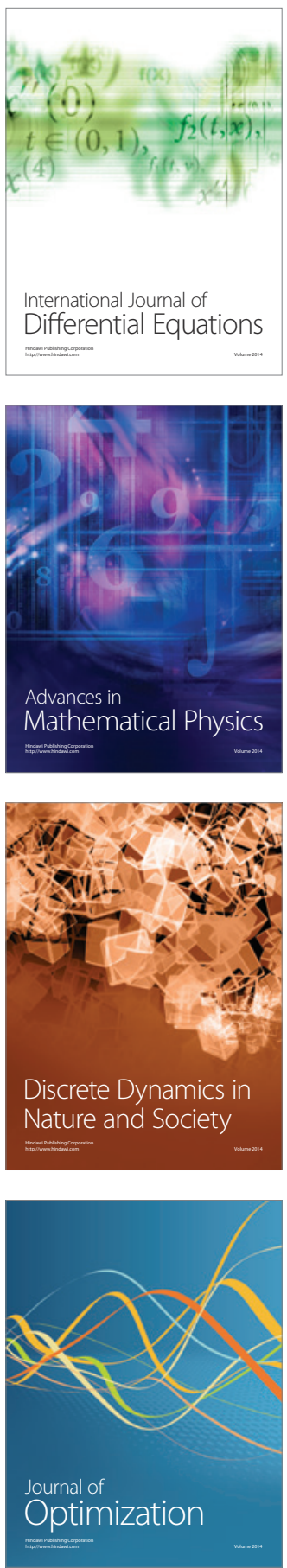